\title{
Tracking of Leptin, Soluble Leptin Receptor, and the Free Leptin Index during Weight Loss and Regain in Children
}

\author{
Jens-Christian Holm ${ }^{a, b}$ Michael Gamborg ${ }^{c}$ Leigh C. Ward ${ }^{e}$ Steen Gammeltoft ${ }^{d}$ \\ Karsten Kaas-lbsen ${ }^{b}$ Berit L. Heitmann ${ }^{c}$ Thorkild I.A. Sørensen $^{c}$ \\ ${ }^{a}$ The Children's Obesity Clinic, Department of Paediatrics, Holbæk University Hospital, Holbæk, \\ ${ }^{\mathrm{b}}$ Department of Paediatrics, Copenhagen University Hospital, Glostrup, \\ ${ }^{\mathrm{c}}$ Institute of Preventive Medicine, Copenhagen University Hospital, Centre for Health and Society, Copenhagen, \\ ${ }^{\mathrm{d}}$ Department of Clinical Biochemistry, Copenhagen University Hospital, Glostrup, Denmark \\ ${ }^{\text {e }}$ School of Chemistry and Molecular Biosciences, University of Queensland, Brisbane, Australia
}

\section{Keywords}

Child - Free leptin index - Leptin - Longitudinal study . Obesity · Puberty · Soluble leptin receptor - Weight loss . Weight regain

\section{Summary}

Objective: To investigate changes in leptin and soluble leptin receptor (SLR) concentrations, and in the free leptin index (FLI) during weight loss and subsequent weight regain; and to ascertain whether these indices remain stable in the rank of the distribution in repeated measures (tracking) during perturbations of weight in obese children. Design and Measurements: In a longitudinal study, 115 obese children were examined during a 12week weight loss programme and 28 months of followup. Height, weight, body composition, Tanner stages, testicular size, time of menarche, and concentrations of leptin and SLR were measured at baseline, on days 14, 33 , and 82, and from months 10, 16, and 28. Results: During weight loss, leptin decreased and the SLR increased. During weight regain, leptin increased and the SLR decreased. The partial correlation coefficients expressing the relationship between leptin and SLR were significant in girls during both weight loss and weight regain, whereas in boys they were much weaker and not significant. Leptin, SLR and FLI exhibited individual-specific levels (tracking) during weight loss and regain in boys and girls. The observed tracking seemed stronger during weight loss than during weight regain. The observed tracking was independent of both baseline body mass index (BMI) standard deviation score (SDS) and pubertal development at baseline and of subsequent changes in BMI SDS and puberty stages. Conclusion: Leptin and the SLR exhibit tracking during weight loss and regain, which indicates individual stability in the leptin system despite challenges of weight.

\section{Introduction}

In spite of the fairly high correlation between leptin and measures of the size of the body fat mass [1] during both weight-stable periods and during weight changes [2, 3], there remain considerable inter-individual differences for a given body fat mass [4]. These differences may be due to known inter-individual differences in other determinants of leptin concentrations, such as testicular size and testosterone [5], menarche [6], concentrations of cortisol, growth hormone [7], and insulin [8], and fasting, overeating, and exercise [9, 10]. Such determinants may vary over time, along with the size of the fat mass, or they may be stable over time irrespective of the size of the body fat mass or perturbations in it over time. Typically, such stable inter-individual differences may originate in individual differences in genetic profiles continuously influencing the phenotype over time or in earlier environmental exposures, perhaps even in the pre- or postnatal period, that lead to persistent influences, usually called programming. Twin studies have suggested that there may be a genetic influence on leptin levels [11-14], but these studies have not fully assessed to what extent this is explained by the genetics of the size of the body fat mass and if the genetic influence is stable over time. If there are such stable determinants, leptin would

\begin{tabular}{ll}
\hline KARGER & $\begin{array}{l}\text { (c) 2011 S. Karger GmbH, Freiburg } \\
1662-4025 / 11 / 0046-0461 \$ 38.00 / 0\end{array}$ \\
Fax +49 7614520714 & $\begin{array}{l}\text { Accessible online at: } \\
\text { www.karger.com/ofa }\end{array}$ \\
www.karger.com &
\end{tabular}


exhibit tracking over time, which can be quantified by the degree of correlation between serial measurements of these indices in the same individuals. Perfect tracking would give a correlation coefficient of 1.0 and no tracking a correlation coefficient of 0 . Tracking of leptin means that concentrations of leptin in a group of individuals maintain the same (or a similar) ranking in the distribution in serial measurements. This means that the same individual would exhibit leptin concentrations in the same percentile band of leptin concentrations for the whole group, irrespective of changes in absolute leptin concentrations.

Intriguingly, it has been shown that over-expression of the soluble leptin receptor (SLR) in ob/ob mice enhances the effect of administered leptin, which suggests that the SLR might interact and contribute directly in leptin functioning [15]. If the SLR has an independent function in leptin action in humans, it should be anticipated to exhibit independent qualities. Knowledge of how much tracking of leptin, SLR, and the free leptin index (FLI) contributes to the development of these indices during weight loss and regain in the same individuals could prove valuable in the analysis of how these indices can be adapted in the clinical predictions of future weight changes.

The aim of the present study is to investigate if these indices show tracking over time during loss of weight induced by enforced modifications of the energy balance components and during the subsequent phase of weight regain. Further, the natural development of leptin during puberty is known to be especially affected by concomitant developments of testosterone and fat mass. Therefore, the analyses of leptin, SLR and FLI were separated by sex.

\section{Material and Methods}

\section{Design}

Groups of obese children were examined on days 1 (baseline), 14, 33, and 82 during the weight loss programme, and at months 10,16 , and 28 during the follow-up regimen. The examinations included interviews and assessment of Tanner stages (gonadal and pubertal), testicular size, weight, height, body composition by bio-impedance, and venous blood samples. The Scientific Ethical Committee of the County of Copenhagen approved the study (KA 97041), and written informed consent was obtained from all participants, as well as from their parents, according to the Helsinki Declaration and its later amendments.

\section{Setting}

The institution 'Julemærkehjemmet', Skælskør, Denmark offers a weight reduction programme consisting of a restricted low-fat diet with a fixed level of energy intake at 6,500-7,000 kJ per day. Follow-up examinations were carried out at the Paediatric Department at the University Hospital in Glostrup.

\section{Children}

During the study, 232 children were identified as eligible to participate, with 120 agreeing to do so. 90 children completed the weight loss programme, 68 engaged in follow-up, but only 44 children completed all examinations in the follow-up programme. For further details during weight loss and weight regain, please see $[2,3]$.

\section{Procedures}

Height was measured by a stadiometer to the nearest $5 \mathrm{~mm}$. Weight was measured to the nearest $0.1 \mathrm{~kg}$ on a SECA Delta scale, model 707 (Simonsen and Weel). The body mass index (BMI) standard deviation score (SDS) was calculated by the least mean squares (LMS) method based on growth data generated in Danish boys and girls [16]. Fat-free mass (FFM) percentages were obtained by bioelectrical impedance spectroscopy using a multi-frequency impedance meter (SFB3; Uniquest Ltd., Australia) and calculated according to the equation proposed by Schaefer et al. [17], validated against total body potassium [17]. We also applied the equation of Wabitsch et al. [18], validated by deuterium dilution [18], which confirmed that changes in FFM were consistent with changes in total weight. The puberty stage was rated according to Tanner stages after evaluation of pubic hair and breasts, and testicular size was measured by Prader's orchidometer.

Venous blood samples were collected from each child between 7:00 am and 8:30 am after an overnight fast during the weight loss regimen, and between 8:00 am and 9:00 am after an overnight fast during follow-up. The serum was frozen at $-80^{\circ} \mathrm{C}$ until analysis. The radioimmunoassay for leptin was performed in duplicate, using the Linco Human Leptin RIA kit (Linco Research Co., St. Louis, MO, USA). The inter-assay coefficient of variation was $4.0 \%$ and the intra-assay coefficient of variation was $7.6 \%$. The human leptin receptor enzyme-linked immunosorbent assay (ELISA) kit from Biovendor Laboratory Medicine (Brno, Czech Republic) was used and performed in duplicate, and showed an interassay coefficient of variation of $17.5 \%$ and an intra-assay coefficient of variation of $16.5 \%$. Owing to relatively high variations, all samples were analysed in duplicate on two separate occasions. According to the manufacturer, the human leptin receptor ELISA measures total SLR, independent of the amount of leptin binding it. The FLI has been proposed as a marker of mainly free leptin in the circulation [19] and may be a better determinant of leptin function [20]. The FLI was calculated as leptin concentration divided by SLR concentration and multiplied by 100 .

\section{Statistical Methods}

Leptin and SLR concentrations were log-transformed in order to achieve approximate normality.

Partial correlation coefficients ( $r$ ) between log-transformed leptin and log-transformed SLR were adjusted for BMI SDS and puberty.

Tracking was investigated using partial correlation coefficients between 2 measures of leptin, SLR, and FLI in the same child adjusted for puberty and BMI SDS at both measurements.

Possible selection bias to drop-out was evaluated by testing whether subjects dropping out differed from those completing the study with respect to age and adiposity and whether re-analysis of subjects with no missing values gave other estimates [21, 22].

Possible selection bias to pubertal development was evaluated by repeating analyses where subjects progressing into puberty were censored.

\section{Results}

The children experienced a significant weight loss $(-1.0 \mathrm{BMI}$ SDS in boys $(\mathrm{p}<0.0001)$ and -0.9 BMI SDS in girls $(\mathrm{p}<0.0001))$ and a significant weight regain $(0.6$ BMI SDS in boys $(\mathrm{p}<0.0001)$ and 0.8 BMI SDS in girls $(\mathrm{p}<0.0001))$ during follow-up. The baseline characteristics of the children, as well as the developments of leptin and BMI SDS during weight loss and weight regain, have been reported previously $[2,3]$.

During the initial phase of weight loss (days 1-82) and during the initial phase of weight regain (day 82 to month 28), leptin and SLR showed an inverse pattern, where leptin de- 
Table 1. Medians and 5 and 95\% percentiles of leptin, SLR, and FLI during weight loss (days 1-82) and subsequent weight gain (months 10-28) in obese children

\begin{tabular}{|c|c|c|c|c|c|c|c|}
\hline & \multicolumn{4}{|l|}{ Days } & \multicolumn{3}{|l|}{ Months } \\
\hline & 1 & 14 & 33 & 82 & 10 & 16 & 28 \\
\hline \multicolumn{8}{|l|}{ Boys } \\
\hline $\mathrm{n}$ & 42 & 36 & 34 & 36 & 26 & 22 & 23 \\
\hline leptin, $\mathrm{ng} / \mathrm{ml}$ & 21.2 & 9.8 & 6.9 & 4.3 & 10.3 & 9.6 & 9.8 \\
\hline leptin, 5 and $95 \%$ percentiles & $8.7 ; 34.8$ & $3.3 ; 21.0$ & $2.5 ; 13.8$ & $2.4 ; 9.9$ & $1.5 ; 34.3$ & $1.9 ; 26.2$ & $3.8 ; 27.1$ \\
\hline $\mathrm{SLR}, \mathrm{U} / \mathrm{ml}$ & 18.5 & 23.6 & 24.4 & 25.7 & 19.2 & 16.8 & 15.4 \\
\hline SLR, 5 and $95 \%$ percentiles & $12.3 ; 31.6$ & $14.7 ; 45.3$ & $16.8 ; 33.0$ & $15.7 ; 49.8$ & $12.0 ; 29.0$ & $11.1 ; 26.9$ & $10.5 ; 22.7$ \\
\hline FLI & 116.6 & 38.5 & 30.0 & 18.6 & 66.0 & 48.2 & 59.5 \\
\hline FLI, 5 and $95 \%$ percentiles & $38.1 ; 202$ & $14.2 ; 87.9$ & $10.5 ; 53.8$ & $7.9 ; 51.0$ & $6.2 ; 211$ & $11.8 ; 157$ & $21.8 ; 205$ \\
\hline partial r & 0.01 & -0.17 & 0.20 & -0.34 & -0.24 & -0.35 & -0.16 \\
\hline $\mathrm{p}$ & \# & $\#$ & $\#$ & $*$ & $\#$ & $\#$ & $\#$ \\
\hline \multicolumn{8}{|l|}{ Girls } \\
\hline $\mathrm{n}$ & 43 & 44 & 40 & 39 & 29 & 32 & 16 \\
\hline leptin, ng/ml & 28.1 & 14.1 & 12.3 & 8.8 & 22.7 & 25.6 & 29.1 \\
\hline leptin, 5 and $95 \%$ percentiles & $16.8 ; 58.4$ & $5.1 ; 32.6$ & $4.9 ; 33.4$ & $4.1 ; 23.5$ & $9.8 ; 43.0$ & $7.9 ; 51.1$ & $13.0 ; 40.7$ \\
\hline $\mathrm{SLR}, \mathrm{U} / \mathrm{ml}$ & 14.9 & 18.4 & 20.4 & 21.2 & 14.1 & 12.8 & 14.3 \\
\hline SLR, 5 and $95 \%$ percentiles & $8.7 ; 23.1$ & $11.4 ; 31.5$ & $10.0 ; 41.2$ & $10.5 ; 40.3$ & $8.0 ; 33.8$ & $6.1 ; 30.9$ & $5.8 ; 24.2$ \\
\hline FLI & 182.5 & 76.7 & 67.1 & 41.1 & 152.1 & 208.5 & 226.1 \\
\hline FLI, 5 and $95 \%$ percentiles & $67.1 ; 757$ & $20.7 ; 258$ & $13.8 ; 332$ & $11.2 ; 176$ & $39.2 ; 520$ & $32.4 ; 837$ & $55.8 ; 591$ \\
\hline partial r & -0.38 & -0.49 & -0.67 & -0.47 & -0.52 & -0.38 & -0.21 \\
\hline $\mathrm{p}$ & $*$ & $* *$ & $* *$ & $*$ & $*$ & $\#$ & \# \\
\hline
\end{tabular}

The partial correlation coefficients express the relationship between leptin and SLR after adjustment for given BMI SDS and puberty stage. $* *=\mathrm{p}<0.001 ; *=\mathrm{p}>0.001$ and $\mathrm{p}<0.05 ;{ }^{*}=\mathrm{p}>0.05$.

$\mathrm{SLR}=$ Soluble leptin receptor, FLI = free leptin index, BMI = body mass index, SDS = standard deviation score.

Table 2. Correlation coefficients comparing a measure of BMI SDS with other measures of BMI SDS in the same child, in boys to the right and over the correlation $=1.0$ diagonal, and in girls to the left and under the correlation $=1.0$ diagonal

\begin{tabular}{|c|c|c|c|c|c|c|c|c|}
\hline Days/Months & & 1 & 14 & 33 & 82 & 10 & 16 & 28 \\
\hline & Girls, $n$ Boys, $n$ & 42 & 29 & 29 & 30 & 24 & 18 & 19 \\
\hline 1 & 50 & 1.0 & $0.99 * *$ & $0.98 * *$ & $0.95 * *$ & $0.87 * *$ & $0.90^{* *}$ & $0.74 * *$ \\
\hline 14 & 44 & $0.99 * *$ & 1.0 & $0.98 * *$ & $0.93 * *$ & $0.85 * *$ & $0.84 * *$ & $0.76^{* *}$ \\
\hline 33 & 39 & $0.98 * *$ & $0.99 *$ & 1.0 & $0.97 * *$ & $0.86 * *$ & $0.87 * *$ & $0.69 * *$ \\
\hline 82 & 38 & $0.92 * *$ & $0.92 * *$ & $0.92 * *$ & 1.0 & $0.88 * *$ & $0.89 * *$ & $0.71 * *$ \\
\hline 10 & 29 & $0.82 * *$ & $0.79 * *$ & $0.81 * *$ & $0.88 * *$ & 1.0 & $0.92 * *$ & $0.74 * *$ \\
\hline 16 & 32 & $0.76^{* *}$ & $0.71 * *$ & $0.73^{* *}$ & $0.72 * *$ & $0.90 * *$ & 1.0 & $0.83 * *$ \\
\hline 28 & 16 & $0.79 * *$ & $0.78 * *$ & $0.77 * *$ & $0.5^{*}$ & $0.79 * *$ & $0.91 * *$ & 1.0 \\
\hline
\end{tabular}

clined and SLR increased during weight loss, while a tendency was observed where leptin increased and SLR decreased during weight regain (table 1). A difference between boys and girls was observed since the partial correlation coefficients expressing the relationship between leptin and SLR were significant in girls during both weight loss and weight regain, whereas in boys they were much weaker and not significant, except for the baseline partial correlation coefficient (table 1). The partial correlation coefficients imply adjustment for BMI SDS and puberty stages.

Tracking of Leptin and Its Soluble Receptor
Tracking of BMI SDS was strong in both boys and girls during both weight loss and regain (table 2).

Table 3 shows the leptin concentrations compared with other measures of leptin in the same child in boys and girls during weight loss and regain. Tracking of leptin appeared stronger in boys since the correlations were significant at a larger number of time points: 18 for boys compared to 7 for girls. In girls, tracking of leptin appeared stronger in weight loss than in regain since the correlations were significant at a larger number of time points: 6 (out of 6 ) for weight loss and 1 
Table 3. Partial correlation coefficients comparing a measure of leptin with other measures of leptin in the same child adjusted for BMI SDS and puberty at all measurements in boys to the right and over the correlation $=1.0$ diagonal, and in girls to the left and under the correlation $=1.0$ diagonal $^{\mathrm{a}}$

\begin{tabular}{|c|c|c|c|c|c|c|c|c|}
\hline Days/months & & 1 & 14 & 33 & 82 & 10 & 16 & 28 \\
\hline & Girls, $n$ Boys, $n$ & 42 & 29 & 29 & 30 & 24 & 18 & 19 \\
\hline 1 & 50 & 1.0 & $0.84 * *$ & $0.74 * *$ & $0.62 * *$ & $0.73 * *$ & $0.75 * *$ & $0.66^{*}$ \\
\hline 14 & 44 & $0.71 *$ & 1.0 & $0.77 * *$ & $0.72 * *$ & $0.74 * *$ & $0.66^{*}$ & $0.68 *$ \\
\hline 33 & 39 & $0.53 *$ & $0.80 * *$ & 1.0 & $0.65 * *$ & $0.74 * *$ & $0.68 *$ & $0.63 *$ \\
\hline 82 & 38 & $0.40 *$ & $0.65^{* *}$ & $0.66^{* *}$ & 1.0 & $0.57 * *$ & $0.27^{\#}$ & $0.38^{\#}$ \\
\hline 10 & 29 & $0.32^{\#}$ & $0.31^{\#}$ & $0.29^{\#}$ & $0.06^{\#}$ & 1.0 & $0.75^{* *}$ & $0.77 * *$ \\
\hline 16 & 32 & $0.36^{\#}$ & $0.39^{\#}$ & $0.24^{\#}$ & $0.49 *$ & $-0.1^{\#}$ & 1.0 & $0.57^{\#}$ \\
\hline 28 & 16 & $-0.16^{\#}$ & $-0.005^{\#}$ & $-0.08^{\#}$ & $-0.11^{\#}$ & $-0.003^{\#}$ & $0.62 *$ & 1.0 \\
\hline
\end{tabular}

$* * \mathrm{p}<0.001 ; * \mathrm{p}>0.001$ and $\mathrm{p}<0.05 ;{ }^{*} \mathrm{p}>0.05$.

${ }^{a}$ Partial means adjustment for BMI SDS and puberty stages in the correlation analysis.
Table 4. Partial correlation coefficients comparing a measure of SLR with other measures of SLR in the same child adjusted for BMI SDS and puberty at all measurements in boys to the right and over the correlation $=1.0$ diagonal, and in girls to the left and under the correlation $=1.0$ diagonal $^{\mathrm{a}}$

Table 5. Partial correlation coefficients comparing a measure of FLI with other measures of FLI in the same child adjusted for BMI SDS and puberty at all measurements in boys to the right and over the correlation $=$ 1.0 diagonal, and in girls to the left and under the correlation $=1.0$ diagonal $^{\mathrm{a}}$

\begin{tabular}{|c|c|c|c|c|c|c|c|c|}
\hline Days/months & & 1 & 14 & 33 & 82 & 10 & 16 & 28 \\
\hline & Girls, $\mathrm{n}$ Boys, $\mathrm{n}$ & 42 & 29 & 29 & 30 & 24 & 18 & 19 \\
\hline 1 & 50 & 1.0 & $0.59 *$ & $0.54^{*}$ & $0.28^{\#}$ & $0.49^{*}$ & $0.21^{\#}$ & $0.24^{\#}$ \\
\hline 14 & 44 & $0.86 * *$ & 1.0 & $0.61^{* *}$ & $0.60 * *$ & $0.33^{\#}$ & $0.62^{*}$ & $0.27^{\#}$ \\
\hline 33 & 39 & $0.74 * *$ & $0.77 * *$ & 1.0 & $0.59^{*}$ & $0.70 * *$ & $0.36^{\#}$ & $0.34^{\#}$ \\
\hline 82 & 38 & $0.46^{*}$ & $0.59 * *$ & $0.70 * *$ & 1.0 & $0.67 * *$ & $0.70^{*}$ & $0.54 *$ \\
\hline 10 & 29 & $0.72 * *$ & $0.50 *$ & $0.50^{*}$ & $0.55^{*}$ & 1.0 & $0.81^{* *}$ & $0.68^{*}$ \\
\hline 16 & 32 & $0.41^{*}$ & $0.24^{\#}$ & $0.23^{\#}$ & $0.35^{\#}$ & $0.65 * *$ & 1.0 & $0.57^{\#}$ \\
\hline 28 & 16 & $0.36^{\#}$ & $0.54^{\#}$ & $0.39^{\#}$ & $0.50^{\#}$ & $0.76^{*}$ & $-0.23^{\#}$ & 1.0 \\
\hline
\end{tabular}

**p $<0.001 ;{ }^{*} \mathrm{p}>0.001$ and $\mathrm{p}<0.05 ;{ }^{*} \mathrm{p}>0.05$.

apartial means adjustment for BMI SDS and puberty stages in the correlation analysis.

\begin{tabular}{|c|c|c|c|c|c|c|c|c|}
\hline Days/months & & 1 & 14 & 33 & 82 & 10 & 16 & 28 \\
\hline & Girls, $\mathrm{n}$ Boys, $\mathrm{n}$ & 42 & 29 & 29 & 30 & 24 & 18 & 19 \\
\hline 1 & 50 & 1.0 & $0.65^{* *}$ & $0.44^{*}$ & $0.35^{*}$ & $0.64 *$ & $0.46^{\#}$ & $0.62 *$ \\
\hline 14 & 44 & $0.83 * *$ & 1.0 & $0.65 * *$ & $0.64 * *$ & $0.70^{*}$ & $0.69 *$ & $0.79 *$ \\
\hline 33 & 39 & $0.71 * *$ & $0.81 * *$ & 1.0 & $0.65^{* *}$ & $0.77 * *$ & $0.63^{*}$ & $0.67 *$ \\
\hline 82 & 38 & $0.39 *$ & $0.62 * *$ & $0.70 * *$ & 1.0 & $0.59^{*}$ & $0.48 *$ & $0.52 *$ \\
\hline 10 & 29 & $0.53^{*}$ & $0.41^{\#}$ & $0.40^{\#}$ & $0.29^{\#}$ & 1.0 & $0.76^{*}$ & $0.84 * *$ \\
\hline 16 & 32 & $0.37^{\#}$ & $0.35^{\#}$ & $0.41^{*}$ & $0.52 *$ & $0.24^{\#}$ & 1.0 & $0.78^{*}$ \\
\hline 28 & 16 & $0.10^{\#}$ & $0.10^{\#}$ & $0.008^{\#}$ & $0.09^{\#}$ & $0.33^{\#}$ & $0.21^{\#}$ & 1.0 \\
\hline
\end{tabular}

$* *=\mathrm{p}<0.001 ; *=\mathrm{p}>0.001$ and $\mathrm{p}<0.05 ;^{*}=\mathrm{p}>0.05$.

${ }^{\text {a } P a r t i a l ~ m e a n s ~ a d j u s t m e n t ~ f o r ~ B M I ~ S D S ~ a n d ~ p u b e r t y ~ s t a g e s ~ i n ~ t h e ~ c o r r e l a t i o n ~ a n a l y s i s . ~}$ (out of 3) for regain, but this tendency was less in boys: 6 (out of 6) for weight loss and 2 (out of 3 ) for regain. The partial correlation coefficients imply adjustment for BMI SDS and puberty stages.

Tracking of the SLR appeared stronger in weight loss than in regain in girls since the correlations were significant at a larger number of time points: 11 (out of 12) for weight loss in both sexes and 0 (out of 3 ) for regain in girls and 3 (out of 3 ) for regain in boys (table 4). The partial correlation coefficients imply adjustment for BMI SDS and puberty stages.
Tracking of the FLI appeared strong in weight loss and in regain in both sexes: 11 significant correlation coefficients (out of 12) for weight loss in both sexes and 2 (out of 3 ) in both sexes for regain (table 5). The partial correlation coefficients imply adjustment for BMI SDS and puberty stages.

Figure 1a, b shows the partial correlation coefficients of leptin (solid line) and SLR (dotted line) with 95\% confidence intervals (CI) during weight loss and regain in boys and girls. The correlation coefficients express the relationship compar- 

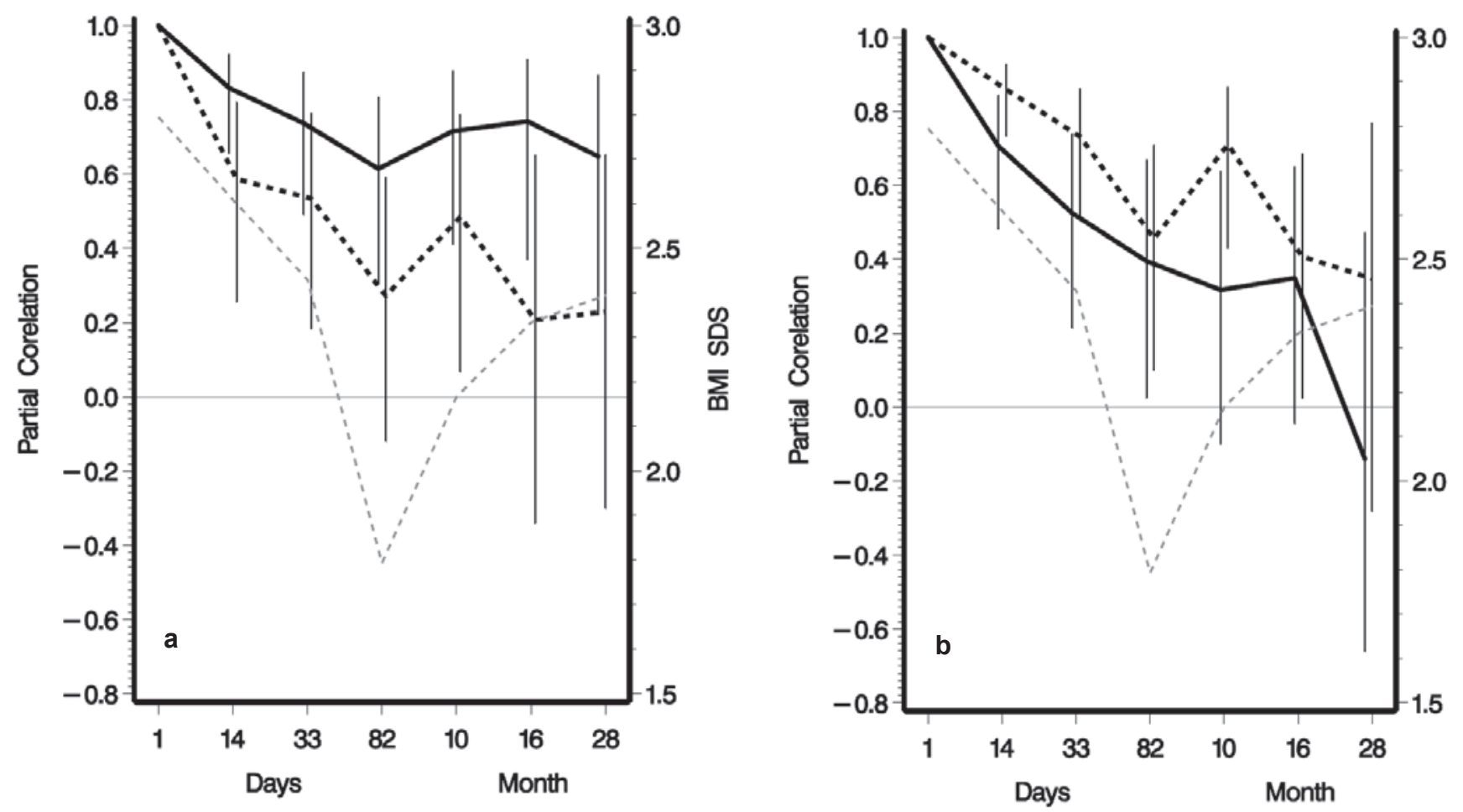

Fig. 1. Changes in the partial correlation coefficients of leptin (solid line) and SLR (dotted line) with $95 \%$ CI during weight loss and regain in (a) boys and (b) girls. The correlation coefficients express the relationship comparing baseline measures of leptin (solid line) with 6 subsequent measures of leptin in the same child and baseline measures of SLR (dotted line) with 6 subsequent measures of SLR in the same child. Concomitant measures of BMI SDS (thin dotted line) show weight loss and regain in boys. The partial correlation coefficients were adjusted for concomitant changes in BMI SDS and puberty stage.

ing baseline measures of leptin (solid line) with 6 subsequent measures of leptin in the same child and baseline measures of SLR (dotted line) with 6 subsequent measures of SLR in the same child. The partial correlations imply adjustment for concomitant changes in BMI SDS and puberty stage. Concomitant changes in BMI SDS (thin dotted line) show weight loss and regain in boys.

The strengths of the partial correlation coefficients for leptin were greater than those for SLR in boys (fig. 1a), whereas in girls, the strengths of the partial correlation coefficients of SLR were greater than those for leptin (fig. 1b).

The partial correlation analyses regarding leptin, SLR, and FLI were adjusted for BMI SDS and puberty stage as reported, but all analyses were also carried out without adjusting for BMI SDS or puberty stages, which did not alter the patterns of the correlation relationships between leptin and the SLR and the tracking of leptin and the SLR (data not shown).

In order to evaluate whether attrition biased the findings, analyses of the variance structure, with exclusion of participants with missing values, were repeated in statistical reanalyses [21, 22], which did not alter the relationships found regarding partial correlation between leptin and the SLR and tracking of leptin and the SLR in children with and without missing values (data not shown).
In order to evaluate whether puberty development biased these findings, analyses were repeated while censoring out all children progressing into puberty. Pre-pubertal children were defined as girls before menarche and boys with a testicular volume below $7 \mathrm{ml}$. The analysis of only pre-pubertal children did not alter the relationships found regarding the partial correlation between leptin and the SLR and tracking of leptin and the SLR (data not shown).

\section{Discussion}

Novel findings of this longitudinal study are that leptin, SLR and FLI exhibit tracking during both weight loss and subsequent weight regain. Tracking of leptin and the SLR was independent of baseline BMI and puberty and subsequent changes of BMI and puberty.

A difference in tracking between boys and girls was suggested since leptin and FLI exhibited stronger tracking in boys than in girls. In girls, there was the tendency that tracking seemed stronger during weight loss than during regain, whereas this tendency was not apparent in boys. Further, the partial correlation coefficients expressing the relationship between leptin and SLR were significant in girls during both weight loss and weight regain whereas in boys they 
were much weaker, also suggesting a difference between the genders.

The present study confirms a number of earlier findings. Weight loss is accompanied by decreasing leptin concentrations and increasing SLR concentrations in both genders [23-25], and the opposite effect is seen in weight regain in anorectics [20] and in malnourished children [26]. However, it should be appreciated that these studies are primarily crosssectional or 'before-and-after' weight change studies, and do not offer the same possibility to evaluate concomitant changes during either weight loss or regain.

The longitudinal design of the present study had the implication that weight loss was a forced action in a controlled environment whereas the weight regain occurred in a free environment at home, where the energy balance seemed to restore a degree of obesity during follow-up that was comparable with pre-weight loss (baseline). Tracking seemed stronger in weight loss, though significant tracking was also observed during regain, which may suggest that the observed changes in the leptin axis seemed competent and not put out of order by either forced weight loss or during an intrinsicrestoration regulation towards weight regain.

In earlier studies in these children, it has been shown during weight loss in boys and girls that leptin declined more than anticipated from the cross-sectional associations between leptin and body weight. This suggests dissociation in the leptin-weight relationship that may contribute to the general variability in leptin concentrations observed in obese subjects [2]. During weight regain, proportional increases in leptin and BMI SDS were demonstrated, suggesting an intact leptin response during re-accumulation of fat. At the same time, it was shown that leptin concentrations were restored to a level aligned with pre-weight loss during continuous weight regain, which suggests an inefficient leptin control exerted by leptin on weight regain [3]. These findings suggest that leptin plays an active role in energy balance regulation, but that this effect may be attenuated during continuous weight loss. Therefore, it is intriguing that leptin and its soluble receptor show tracking within an individual, and especially so during challenges of weight in boys and girls, further suggesting a genetic influence compatible with an endocrine body weight regulatory system. It is also intriguing that tracking seemed to be less pronounced during weight regain. This may have resulted from bias due to selective attrition during the course of the study (discussed further below), but it could also reflect that the leptin system became increasingly dysregulated during continuous weight regain.

Although tracking per se appears not to have been demonstrated previously, Jordan et al. [27] showed that circulating SLR concentrations, and leptin concentrations, bound or free, exhibited adjusted heritability estimates of 0.28 for free leptin, 0.73 for bound leptin, and 0.55 for SLR, in 24 monozygotic and 22 dizygotic twin pairs, suggesting an intrinsic genetic influence, which could be compatible with tracking. In com- parison, heritability estimates reported in twin studies for the trend of BMI from early childhood to late middle age ranged from 0.57 to 0.86 [28], resembling the leptin and SLR estimates of tracking.

The FLI has been developed and suggested as a marker of the presumed free leptin concentrations [19, 20, 29]. Not surprisingly, FLI exhibited tracking, as did its constituents, leptin and SLR. It is less certain whether this marker of free leptin concentrations translates into reduced or increased leptin actions. However, during weight loss, the FLI decreased, which may be compatible with decreasing concentrations of free leptin (free leptin was not measured in the present study), whereas the FLI increased during weight regain in girls but remained stable in boys, which might indicate increased free leptin concentrations during weight regain in girls.

These findings are in accord with available data showing that SLR binds the majority of leptin in the circulation [30,31] in lean children and spills leptin into an expanding free leptin pool in increasingly obese children [32,33].

A difference between boys and girls regarding tracking was observed since tracking was stronger in boys than in girls, although the relationship between leptin and SLR was stronger in girls. In girls, tracking seemed stronger during weight loss than during regain, whereas this was not obvious in boys. This effect may be due to sex differences in body composition development during puberty [34] or other considerations regarding methodology [35] that may affect leptin, SLR, or body fat depots. Therefore, the statistical analysis was repeated excluding those children entering puberty; however, censoring out pubertal development did not alter the relationships regarding tracking of either leptin or the SLR during either weight loss or weight regain previously found in the whole group.

A number of possible confounding influences on the conclusions should be acknowledged. In the present study, we sought to avoid the diurnal and discordant [36] changes in leptin and SLR concentrations [37], by sampling during fasting.

The SLR ELISA exhibited variability, which occurred even though the measurements were made in duplicate and were later repeated in duplicate. Nevertheless, the SLR concentrations showed significant tracking during changes of weight. Further, no indication was found that measurement uncertainty was unilaterally biased by gender, age or weight status. Therefore, any variability in the SLR ELISA results would have tended to result in an underestimation of the relationships established, since greater variability most likely would weaken the SLR correlations.

Attrition in numbers of participants during the study, though common in weight loss studies [38], always threatens to reduce the statistical power; however, significant findings were found. Nevertheless, attrition may have attributed to the finding that tracking was more pronounced in weight loss than 
in regain. Great effort was put into checking for possible selection bias by exclusion of participants with missing values in statistical re-analyses, which did not alter the correlation relationships in the present study.

According to the findings of tracking of leptin, SLR, and FLI during changes in weight in the present longitudinal study, serial measurements of leptin and SLR simultaneously provide information about the leptin control system and, in turn, energy status and flux. Such an approach might improve the clinical assessment using the leptin system of later weight developments [39]. However, this needs to be supported by information regarding normal ranges of leptin and the SLR during weight changes in childhood, as well as characterization of concentrations of leptin and the SLR with regard to maintenance of an individual stable weight in combination with other phenotypical traits (age, BMI SDS, puberty etc.) before these indices can be adapted in the clinical assessments of future weight changes.

\section{Acknowledgements}

This work was supported by grants from the P. Carl Petersens Foundation, the Health Insurance Foundation, the Christmas Stamp Foundation, the Danish Hospital Foundation for Medical Research, the Region of Copenhagen, the Faeroe Islands and Greenland, Danish Medical Research Council, the Queen Louise Children's Hospital Research Foundation, the King Christian the Xth Foundation, the Managing Director Ib Henriksens Foundation, the Rosalie Petersen Foundation, the Glasshoff Foundation, the Novo Nordisk Foundation and the Dagmar Marshall Foundation. Further, Mrs. Oda Troest provided invaluable expert assistance regarding data retrieving and handling. The study is part of the research activities in the Danish Obesity Research Centre (DanORC, www.danorc.dk) and the Danish Childhood Obesity Biobank: http://ClinicalTrials.gov ID no.: NCT00928473.

\section{Disclosure Statement}

All authors declare that there is no conflict of interest that could be perceived as prejudicing the impartiality of the research project.

\section{References}

1 Hassink SG, Sheslow DV, de Lancey E, Opentanova I, Considine RV, Caro JF: Serum leptin in children with obesity: relationship to gender and development. Pediatrics 1996;98(2 Pt 1):201-203.

- 2 Holm J-C, Gamborg M, Ibsen KK, Gammeltoft S, Ward L, Heitmann BL, Sørensen TIA: Time course and determinants of leptin decline during weight loss in obese boys and girls. Int J Ped Obes 2007;2:2-10.

>3 Holm J-C, Gamborg M, Ward L, Ibsen KK, Gammeltoft S, Sørensen TIA, Heitmann BL: Longitudinal analysis of leptin variation during weight regain after weight loss in obese children. Obes Facts 2009;2:243-248.

4 Considine RV, Sinha MK, Heiman ML, Kriauciunas A, Stephens TW, Nyce MR, Ohannesian JP, Marco CC, McKee LJ, Bauer, TL: Serum immunoreactive-leptin concentrations in normal-weight and obese humans. N Engl J Med 1996;334:292-295.

$\checkmark 5$ Wabitsch M, Blum WF, Muche R, Braun M, Hube F, Rascher W, Heinze E, Teller W, Hauner H: Contribution of androgens to the gender difference in leptin production in obese children and adolescents. J Clin Invest 1997;100:808-813.

6 Hardie L, Trayhurn P, Abramovich D, Fowler P: Circulating leptin in women: a longitudinal study in the menstrual cycle and during pregnancy. Clin Endocrinol 1997;47:101-106.

7 Berneis K, Vosmeer S, Keller U: Effects of glucocorticoids and of growth hormone on serum leptin concentrations in man. Eur J Endocrinol 1996;135: 663-665.

8 Kolaczynski JW, Nyce MR, Considine RV, Boden G, Nolan JJ, Henry R, Mudaliar SR, Olefsky J, Caro JF: Acute and chronic effects of insulin on leptin production in humans: Studies in vivo and in vitro. Diabetes 1996;45:699-701.

9 Kolaczynski JW, Considine RV, Ohannesian J, Marco C, Opentanova I, Nyce MR, Myint M, Caro JF: Responses of leptin to short-term fasting and refeeding in humans: a link with ketogenesis but not ketones themselves. Diabetes 1996;45:1511-1515.
10 van Aggel-Leijssen DP, van Baak MA, Tenenbaum R, Campfield LA, Saris WH: Regulation of average $24 \mathrm{~h}$ human plasma leptin level; the influence of exercise and physiological changes in energy balance. Int J Obes Relat Metab Disord 1999; 23:151-158.

11 Kaprio J, Eriksson J, Lehtovirta M, Koskenvuo M, Tuomilehto J: Heritability of leptin levels and the shared genetic effects on body mass index and leptin in adult Finnish twins. Int J Obes Relat Metab Disord 2001;25:132-137.

12 Jamshidi Y, Snieder H, Ge D, Spector TD, O'Dell $\mathrm{SD}$ : The $\mathrm{SH} 2 \mathrm{~B}$ gene is associated with serum leptin and body fat in normal female twins. Obesity 2007; 15:5-9.

13 Chen Y, Snieder H, Wang X, Kaviya B, McCaffrey C, Spector TD, Carter ND, O'Dell SD: Proopiomelanocortin gene variants are associated with serum leptin and body fat in a normal female population. Eur J Hum Genet 2005;13:772-780.

14 Hasselbalch AL, Benyamin B, Visscher PM, Heitmann BL, Kyvik KO, Sørensen TIA: Common genetic components of obesity traits and serum leptin. Obesity 2008;16:2723-2729.

15 Huang L, Wang Z, Li C: Modulation of circulating leptin levels by its soluble receptor. J Biol Chem 2001;276:6343-6349.

16 Nysom KMC, Hutchings B, Michaelsen KF: Body mass index of 0 to 45 -y-old Danes: reference values and comparison with published European reference values. Int J Obes Relat Metab Disord 2001;25: 177-184.

17 Schaefer F, Georgi M, Zieger A, Scharer K: Usefulness of bioelectric impedance and skinfold measurements in predicting fat-free mass derived from total body potassium in children. Pediatr Res 1994;35:617-624.

18 Wabitsch M, Braun U, Heinze E, Muche R, Mayer H, Teller W, Fusch C: Body composition in 5-18-yold obese children and adolescents before and after weight reduction as assessed by deuterium dilution and bioelectrical impedance analysis. Am J Clin Nutr 1996;64:1-6.
9 Kratzsch J, Lammert A, Bottner A, Seidel B, Mueller G, Thierry J, Hebebrand J, Kiess W: Circulating soluble leptin receptor and free leptin index during childhood, puberty, and adolescence. J Clin Endocrinol Metab 2002;87:4587-4594.

20 Misra M, Miller K, Almazan C, Ramaswamy K, Aggarwal A, Herzog D, Neubauer G, Breu J, Klibanski A: Hormonal and body composition predictors of soluble leptin receptor, leptin, and free leptin index in adolescent girls with anorexia nervosa and controls and relation to insulin sensitivity. J Clin Endocrinol Metab 2004;89:3486-3495.

21 Diggle P, Heagerty P, Liang K-Y, Zeger S: Analysis of Longitudinal Data, ed 2. Oxford, Oxford University Press, 2002.

22 Molenberghs G, Kenward MG: Missing Data in Clinical Studies. Chichester, John Wiley \& Sons, 2007.

23 Reinehr T, Kratzsch J, Kiess W, Andler W: Circulating soluble leptin receptor, leptin, and insulin resistance before and after weight loss in obese children. Int J Obes 2005;29:1230-1235.

24 Laimer M, Ebenbichler CF, Kaser S, Sandhofer A, Weiss H, Nehoda H, Nehoda H, Aigner F, Patsch JR: Weight loss increases soluble leptin receptor levels and the soluble receptor bound fraction of leptin. Obes Res 2002;10:597-601.

25 Gajewska J, Weker H, Ambroszkiewicz J, Chelchowska M, Dylag H, Oltarzewski M, LaskowskaKlita T: Can leptin and soluble leptin receptor concentrations be used in assessing the efficacy of weight reduction programme in prepubertal obese children? Preliminary report. Med Wieku Rozwoj 2010;13:237-243.

26 Stein K, Vasquez-Garibay E, Kratzsch J, RomeroVelarde E, Jahreis G: Influence of nutritional recovery on the leptin axis in severely malnourished children. J Clin Endocrinol Metab 2006;91:1021-1026.

27 Jordan J, Brabant G, Brinsuk M, Tank J, Horn R, Luft F, Busjahn A: Heretability of free and receptor-bound leptin in twins. Am J Physiol Integr Comp Physiol 2005;288:R1411-R1416. 
28 Silventoinen K, Kaprio J: Genetics of tracking of body mass index from birth to late middle age: evidence from twin and family studies. Obes Facts 2009;2:196-202.

29 Owecki M, Nikisch E, Miczke A, Pupek-Musialik D, Sowinski J: Leptin, soluble leptin receptors, free leptin index, and their relationship with insulin resistance and BMI: High normal BMI is the threshold for serum leptin increase in humans. Horm Metab Res 2010;42:585-589.

-30 Rock FL, Peterson D, Weig BC, Kastelein RA, Bazan JF: Binding of leptin to the soluble ectodomain of recombinant leptin receptor: a kinetic analysis by surface plasmon resonance. Horm Metab Res 1996;28:748-750.

-31 Lammert A, Kiess W, Bottner A, Glasow A, Kratzsch J: Soluble leptin receptor represents the main leptin binding activity in human blood. Biochem Biophys Res Commun 2001;283:982-988.
32 Sinha MK, Opentanova I, Ohannesian JP, Kolaczynski JW, Heiman ML, Hale J, Becker GW, Bowsher RR, Stephens TW, Caro JF: Evidence of free and bound leptin in human circulation. Studies in lean and obese subjects and during short-term fasting. J Clin Invest 1996;98:1277-1282.

33 Houseknecht KL, Mantzoros CS, Kuliawat R, Hadro E, Flier JS, Kahn BB: Evidence for leptin binding to proteins in serum of rodents and humans: modulation with obesity. Diabetes 1996;45: 1638-1643.

34 Ahmed ML, Ong KK, Morrell DJ, Cox L, Drayer N, Perry L, Preece MA, Dunger DB: Longitudinal study of leptin concentrations during puberty: sex differences and relationship to changes in body composition. J Clin Endocrinol Metab 1999;84:899-905.

35 Jenkins AB, Campbell LV: Does relative leptinemia predict weight gain in humans? Obes Res 2003; 11:373-374.
36 Chan JL, Bluher S, Yiannakouris N, Suchard MA Kratzsch J, Mantzoros CS: Regulation of circulating soluble leptin receptor levels by gender, adiposity, sex steroids, and leptin: observational and interventional studies in humans. Diabetes 2002;51: 2105-2112.

37 Licinio J, Mantzoros C, Negrao AB, Cizza G, Wong ML, Bongiorno PB, Chrousos GP, Karp B, Allen C, Flier JS, Gold PW: Human leptin levels are pulsatile and inversely related to pituitaryadrenal function. Nat Med 1997;3:575-579.

38 Gilden TA, Wadden TA: The evolution of verylow-calory diets: an update and meta-analysis. Obesity 2006;14:1283-1293.

39 Reinehr T, Kleber M, De Sousa G, Andler W: Leptin concentrations are a predictor of overweight reduction in a lifestyle intervention. Int J Ped Obes 2009:1-9. 